\title{
An AQCQ-functional equation in matrix Banach spaces
}

\author{
Choonkil Park', Jung Rye Lee² and Dong Yun Shin*
}

"Correspondence: dyshin@uos.ac.kr ${ }^{3}$ Department of Mathematics, University of Seoul, Seoul, 130-743, Korea

Full list of author information is available at the end of the article

\author{
Abstract \\ Using the fixed point method, we prove the Hyers-Ulam stability of an \\ additive-quadratic-cubic-quartic functional equation in matrix normed spaces. \\ MSC: Primary 47L25; 47H10; 39B82; 46L07; 39B52 \\ Keywords: operator space; fixed point; Hyers-Ulam stability; \\ additive-quadratic-cubic-quartic functional equation
}

\section{Introduction and preliminaries}

The abstract characterization given for linear spaces of bounded Hilbert space operators in terms of matricially normed spaces [1] implies that quotients, mapping spaces and various tensor products of operator spaces may again be regarded as operator spaces. Owing in part to this result, the theory of operator spaces is having an increasingly significant effect on operator algebra theory (see [2]).

The proof given in [1] appealed to the theory of ordered operator spaces [3]. Effros and Ruan [4] showed that one can give a purely metric proof of this important theorem by using the technique of Pisier [5] and Haagerup [6] (as modified in [7]).

The stability problem of functional equations originated from a question of Ulam [8] concerning the stability of group homomorphisms.

The functional equation

$$
f(x+y)=f(x)+f(y)
$$

is called the Cauchy additive functional equation. In particular, every solution of the Cauchy additive functional equation is said to be an additive mapping. Hyers [9] gave the first affirmative partial answer to the question of Ulam for Banach spaces. Hyers' theorem was generalized by Aoki [10] for additive mappings and by TM Rassias [11] for linear mappings by considering an unbounded Cauchy difference. A generalization of the TM Rassias theorem was obtained by Găvruta [12] by replacing the unbounded Cauchy difference by a general control function in the spirit of TM Rassias' approach.

In 1990, TM Rassias [13] during the 27th International Symposium on Functional Equations asked the question whether such a theorem can also be proved for $p \geq 1$. In 1991, Gajda [14], following the same approach as in TM Rassias [11], gave an affirmative solution to this question for $p>1$. It was shown by Gajda [14], as well as by TM Rassias and Šemrl [15], that one cannot prove a TM Rassias' type theorem when $p=1$ ( $c f$. the books of Czerwik [16], Hyers et al. [17]).

\section{照 Springer}

(C) 2013 Park et al.; licensee Springer. This is an Open Access article distributed under the terms of the Creative Commons Attribution License (http://creativecommons.org/licenses/by/2.0), which permits unrestricted use, distribution, and reproduction in any medium, provided the original work is properly cited. 
In 1982, JM Rassias [18] followed the innovative approach of the TM Rassias' theorem [11] in which he replaced the factor $\|x\|^{p}+\|y\|^{p}$ by $\|x\|^{p} \cdot\|y\|^{q}$ for $p, q \in \mathbb{R}$ with $p+q \neq 1$.

The functional equation

$$
f(x+y)+f(x-y)=2 f(x)+2 f(y)
$$

is called a quadratic functional equation. In particular, every solution of the quadratic functional equation is said to be a quadratic mapping. A Hyers-Ulam stability problem for the quadratic functional equation was proved by Skof [19] for mappings $f: X \rightarrow Y$, where $X$ is a normed space and $Y$ is a Banach space. Cholewa [20] noticed that the theorem of Skof is still true if the relevant domain $X$ is replaced by an Abelian group. Czerwik [21] proved the Hyers-Ulam stability of the quadratic functional equation.

In [22], Jun and Kim considered the following cubic functional equation:

$$
f(2 x+y)+f(2 x-y)=2 f(x+y)+2 f(x-y)+12 f(x) .
$$

It is easy to show that the function $f(x)=x^{3}$ satisfies functional equation (1.1), which is called a cubic functional equation and every solution of the cubic functional equation is said to be a cubic mapping.

In [23], Lee et al. considered the following quartic functional equation:

$$
f(2 x+y)+f(2 x-y)=4 f(x+y)+4 f(x-y)+24 f(x)-6 f(y) .
$$

It is easy to show that the function $f(x)=x^{4}$ satisfies functional equation (1.2), which is called a quartic functional equation, and every solution of the quartic functional equation is said to be a quartic mapping. The stability problems of several functional equations have been extensively investigated by a number of authors and there are many interesting results concerning this problem (see [24-33]).

We will use the following notations:

$e_{j}=(0, \ldots, 0,1,0, \ldots, 0)$;

$E_{i j}$ is that $(i, j)$-component is 1 and the other components are zero;

$E_{i j} \otimes x$ is that $(i, j)$-component is $x$ and the other components are zero;

For $x \in M_{n}(X), y \in M_{k}(X)$,

$$
x \oplus y=\left(\begin{array}{ll}
x & 0 \\
0 & y
\end{array}\right) .
$$

Note that $\left(X,\left\{\|\cdot\|_{n}\right\}\right)$ is a matrix normed space if and only if $\left(M_{n}(X),\|\cdot\|_{n}\right)$ is a normed space for each positive integer $n$ and $\|A x B\|_{k} \leq\|A\|\|B\|\|x\|_{n}$ holds for $A \in M_{k, n}, x=\left(x_{i j}\right) \in$ $M_{n}(X)$ and $B \in M_{n, k}$, and that $\left(X,\left\{\|\cdot\|_{n}\right\}\right)$ is a matrix Banach space if and only if $X$ is a Banach space and $\left(X,\left\{\|\cdot\|_{n}\right\}\right)$ is a matrix normed space.

Let $E, F$ be vector spaces. For a given mapping $h: E \rightarrow F$ and a given positive integer $n$, define $h_{n}: M_{n}(E) \rightarrow M_{n}(F)$ by

$$
h_{n}\left(\left[x_{i j}\right]\right)=\left[h\left(x_{i j}\right)\right]
$$

for all $\left[x_{i j}\right] \in M_{n}(E)$. 
Let $X$ be a set. A function $d: X \times X \rightarrow[0, \infty]$ is called a generalized metric on $X$ if $d$ satisfies

(1) $d(x, y)=0$ if and only if $x=y$;

(2) $d(x, y)=d(y, x)$ for all $x, y \in X$;

(3) $d(x, z) \leq d(x, y)+d(y, z)$ for all $x, y, z \in X$.

We recall a fundamental result in fixed point theory.

Theorem 1.1 $[34,35]$ Let $(X, d)$ be a complete generalized metric space and let $J: X \rightarrow X$ be a strictly contractive mapping with Lipschitz constant $\alpha<1$. Then, for each given element $x \in X$, either

$$
d\left(J^{n} x, J^{n+1} x\right)=\infty
$$

for all nonnegative integers $n$ or there exists a positive integer $n_{0}$ such that

(1) $d\left(J^{n} x, J^{n+1} x\right)<\infty, \forall n \geq n_{0}$;

(2) the sequence $\left\{J^{n} x\right\}$ converges to a fixed point $y^{\prime \prime}$ of $J$;

(3) $y^{*}$ is the unique fixed point of $J$ in the set $Y=\left\{y \in X \mid d\left(J^{n_{0}} x, y\right)<\infty\right\}$;

(4) $d\left(y, y^{*}\right) \leq \frac{1}{1-\alpha} d(y, J y)$ for all $y \in Y$.

In 1996, Isac and Rassias [36] were the first to provide applications of stability theory of functional equations for the proof of new fixed point theorems with applications. By using fixed point methods, the stability problems of several functional equations have been extensively investigated by a number of authors (see [37-43]).

In this paper, we prove the Hyers-Ulam stability of the following additive-quadraticcubic-quartic functional equation:

$$
\begin{aligned}
f(x+2 y)+f(x-2 y)= & 4 f(x+y)+4 f(x-y)-6 f(x) \\
& +f(2 y)+f(-2 y)-4 f(y)-4 f(-y)
\end{aligned}
$$

in matrix normed spaces by using the fixed point method.

One can easily show that an odd mapping $f: X \rightarrow Y$ satisfies (1.3) if and only if the odd mapping $f: X \rightarrow Y$ is an additive-cubic mapping, i.e.,

$$
f(x+2 y)+f(x-2 y)=4 f(x+y)+4 f(x-y)-6 f(x) .
$$

It was shown in [44, Lemma 2.2] that $g(x):=f(2 x)-2 f(x)$ and $h(x):=f(2 x)-8 f(x)$ are cubic and additive, respectively, and that $f(x)=\frac{1}{6} g(x)-\frac{1}{6} h(x)$.

One can easily show that an even mapping $f: X \rightarrow Y$ satisfies (1.3) if and only if the even mapping $f: X \rightarrow Y$ is a quadratic-quartic mapping, i.e.,

$$
f(x+2 y)+f(x-2 y)=4 f(x+y)+4 f(x-y)-6 f(x)+2 f(2 y)-8 f(y) .
$$

It was shown in [45, Lemma 2.1] that $g(x):=f(2 x)-4 f(x)$ and $h(x):=f(2 x)-16 f(x)$ are quartic and quadratic, respectively, and that $f(x)=\frac{1}{12} g(x)-\frac{1}{12} h(x)$.

Throughout this paper, let $\left(X,\left\{\|\cdot\|_{n}\right\}\right)$ be a matrix normed space and $\left(Y,\left\{\|\cdot\|_{n}\right\}\right)$ be a matrix Banach space. 


\section{Hyers-Ulam stability of AQCQ-functional equation (1.3) in matrix normed spaces: odd mapping case}

In this section, we prove the Hyers-Ulam stability of AQCQ-functional equation (1.3) in matrix normed spaces for an odd mapping case.

Lemma 2.1 Let $\left(X,\left\{\|\cdot\|_{n}\right\}\right)$ be a matrix normed space. Then:

(1) $\left\|E_{k l} \otimes x\right\|_{n}=\|x\|$ for $x \in X$.

(2) $\left\|x_{k l}\right\| \leq\left\|\left[x_{i j}\right]\right\|_{n} \leq \sum_{i, j=1}^{n}\left\|x_{i j}\right\|$ for $\left[x_{i j}\right] \in M_{n}(X)$.

(3) $\lim _{n \rightarrow \infty} x_{n}=x$ if and only if $\lim _{n \rightarrow \infty} x_{i j n}=x_{i j}$ for $x_{n}=\left[x_{i j n}\right], x=\left[x_{i j}\right] \in M_{k}(X)$.

Proof (1) Since $E_{k l} \otimes x=e_{k}^{*} x e_{l}$ and $\left\|e_{k}^{*}\right\|=\left\|e_{l}\right\|=1,\left\|E_{k l} \otimes x\right\|_{n} \leq\|x\|$. Since $e_{k}\left(E_{k l} \otimes x\right) e_{l}^{*}=x$, $\|x\| \leq\left\|E_{k l} \otimes x\right\|_{n}$. So $\left\|E_{k l} \otimes x\right\|_{n}=\|x\|$.

(2) Since $e_{k} x e_{l}^{*}=x_{k l}$ and $\left\|e_{k}\right\|=\left\|e_{l}^{*}\right\|=1,\left\|x_{k l}\right\| \leq\left\|\left[x_{i j}\right]\right\|_{n}$. Since $\left[x_{i j}\right]=\sum_{i, j=1}^{n} E_{i j} \otimes x_{i j}$,

$$
\left\|\left[x_{i j}\right]\right\|_{n}=\left\|\sum_{i, j=1}^{n} E_{i j} \otimes x_{i j}\right\|_{n} \leq \sum_{i, j=1}^{n}\left\|E_{i j} \otimes x_{i j}\right\|_{n}=\sum_{i, j=1}^{n}\left\|x_{i j}\right\| .
$$

(3) By

$$
\left\|x_{k l n}-x_{k l}\right\| \leq\left\|\left[x_{i j n}-x_{i j}\right]\right\|_{n}=\left\|\left[x_{i j n}\right]-\left[x_{i j}\right]\right\|_{n} \leq \sum_{i, j=1}^{n}\left\|x_{i j n}-x_{i j}\right\|,
$$

we get the result.

For a mapping $f: X \rightarrow Y$, define $D f: X^{2} \rightarrow Y$ and $D f_{n}: M_{n}\left(X^{2}\right) \rightarrow M_{n}(Y)$ by

$$
\begin{gathered}
D f(a, b):=f(a+2 b)+f(a-2 b)-4 f(a+b)-4 f(a-b)+6 f(a) \\
-f(2 b)-f(-2 b)+4 f(b)+4 f(-b), \\
\begin{aligned}
D f_{n}\left(\left[x_{i j}\right],\left[y_{i j}\right]\right):= & f_{n}\left(\left[x_{i j}\right]+2\left[y_{i j}\right]\right)+f_{n}\left(\left[x_{i j}\right]-2\left[y_{i j}\right]\right)-4 f_{n}\left(\left[x_{i j}\right]+\left[y_{i j}\right]\right) \\
& -4 f_{n}\left(\left[x_{i j}\right]-\left[y_{i j}\right]\right)+6 f_{n}\left(\left[x_{i j}\right]\right)-f_{n}\left(2\left[y_{i j}\right]\right) \\
& -f_{n}\left(-2\left[y_{i j}\right]\right)+4 f_{n}\left(\left[y_{i j}\right]\right)+4 f_{n}\left(-\left[y_{i j}\right]\right)
\end{aligned}
\end{gathered}
$$

for all $a, b \in X$ and all $x=\left[x_{i j}\right], y=\left[y_{i j}\right] \in M_{n}(X)$.

Theorem 2.2 Let $\varphi: X^{2} \rightarrow[0, \infty)$ be a function such that there exists an $\alpha<1$ with

$$
\varphi(a, b) \leq 2 \alpha \varphi\left(\frac{a}{2}, \frac{b}{2}\right)
$$

for all $a, b \in X$. Let $f: X \rightarrow Y$ be an odd mapping satisfying

$$
\left\|D f_{n}\left(\left[x_{i j}\right],\left[y_{i j}\right]\right)\right\|_{n} \leq \sum_{i, j=1}^{n} \varphi\left(x_{i j}, y_{i j}\right)
$$


for all $x=\left[x_{i j}\right], y=\left[y_{i j}\right] \in M_{n}(X)$. Then there exists a unique additive mapping $A: X \rightarrow Y$ such that

$$
\left\|f_{n}\left(2\left[x_{i j}\right]\right)-8 f_{n}\left(\left[x_{i j}\right]\right)-A_{n}\left(\left[x_{i j}\right]\right)\right\|_{n} \leq \sum_{i, j=1}^{n} \frac{1}{1-\alpha}\left(2 \varphi\left(x_{i j}, x_{i j}\right)+\frac{1}{2} \varphi\left(2 x_{i j}, x_{i j}\right)\right)
$$

for all $x=\left[x_{i j}\right] \in M_{n}(X)$.

Proof Let $x_{i j}=0$ and $y_{i j}=0$ except for $(i, j)=(s, t)$ in $(2.2)$.

Putting $y_{s t}=x_{s t}$ in (2.2), we get

$$
\left\|f\left(3 y_{s t}\right)-4 f\left(2 y_{s t}\right)+5 f\left(y_{s t}\right)\right\| \leq \varphi\left(y_{s t}, y_{s t}\right)
$$

for all $y_{s t} \in X$.

Replacing $x_{s t}$ by $2 y_{s t}$ in (2.2), we get

$$
\left\|f\left(4 y_{s t}\right)-4 f\left(3 y_{s t}\right)+6 f\left(2 y_{s t}\right)-4 f\left(y_{s t}\right)\right\| \leq \varphi\left(2 y_{s t}, y_{s t}\right)
$$

for all $y_{s t} \in X$.

By (2.4) and (2.5),

$$
\begin{aligned}
& \left\|f\left(4 y_{s t}\right)-10 f\left(2 y_{s t}\right)+16 f\left(y_{s t}\right)\right\| \\
& \quad \leq\left\|4\left(f\left(3 y_{s t}\right)-4 f\left(2 y_{s t}\right)+5 f\left(y_{s t}\right)\right)\right\|+\left\|f\left(4 y_{s t}\right)-4 f\left(3 y_{s t}\right)+6 f\left(2 y_{s t}\right)-4 f\left(y_{s t}\right)\right\| \\
& \quad=4\left\|f\left(3 y_{s t}\right)-4 f\left(2 y_{s t}\right)+5 f\left(y_{s t}\right)\right\|+\left\|f\left(4 y_{s t}\right)-4 f\left(3 y_{s t}\right)+6 f\left(2 y_{s t}\right)-4 f\left(y_{s t}\right)\right\| \\
& \quad \leq 4 \varphi\left(y_{s t}, y_{s t}\right)+\varphi\left(2 y_{s t}, y_{s t}\right)
\end{aligned}
$$

for all $y_{s t} \in X$. Replacing $y_{s t}$ by $x_{s t}$ and letting $g\left(x_{s t}\right):=f\left(2 x_{s t}\right)-8 f\left(x_{s t}\right)$ in (2.6), we get

$$
\left\|g\left(2 x_{s t}\right)-2 g\left(x_{s t}\right)\right\| \leq 4 \varphi\left(x_{s t}, x_{s t}\right)+\varphi\left(2 x_{s t}, x_{s t}\right)
$$

for all $x_{s t} \in X$. So

$$
\left\|g\left(x_{s t}\right)-\frac{1}{2} g\left(2 x_{s t}\right)\right\| \leq 2 \varphi\left(x_{s t}, x_{s t}\right)+\frac{1}{2} \varphi\left(2 x_{s t}, x_{s t}\right)
$$

for all $x_{s t} \in X$.

Consider the set

$$
S:=\{h: X \rightarrow Y\}
$$

and introduce the generalized metric on $S$ :

$$
d(g, h)=\inf \left\{\mu \in \mathbb{R}_{+}:\|g(a)-h(a)\| \leq \mu\left(2 \varphi(a, a)+\frac{1}{2} \varphi(2 a, a)\right), \forall a \in X\right\},
$$

where, as usual, $\inf \phi=+\infty$. It is easy to show that $(S, d)$ is complete (see $[46,47])$. 
Now we consider the linear mapping $J: S \rightarrow S$ such that

$$
J g(a):=\frac{1}{2} g(2 a)
$$

for all $a \in X$.

Let $g, h \in S$ be given such that $d(g, h)=\varepsilon$. Then

$$
\|g(a)-h(a)\| \leq 2 \varphi(a, a)+\frac{1}{2} \varphi(2 a, a)
$$

for all $a \in X$. Hence

$$
\|J g(a)-J h(a)\|=\left\|\frac{1}{2} g(2 a)-\frac{1}{2} h(2 a)\right\| \leq \alpha\left(2 \varphi(a, a)+\frac{1}{2} \varphi(2 a, a)\right)
$$

for all $a \in X$. So $d(g, h)=\varepsilon$ implies that $d(J g, J h) \leq \alpha \varepsilon$. This means that

$$
d(J g, J h) \leq \alpha d(g, h)
$$

for all $g, h \in S$.

It follows from (2.7) that $d(g, J g) \leq 1$.

By Theorem 1.1, there exists a mapping $A: X \rightarrow Y$ satisfying the following:

(1) $A$ is a fixed point of $J$, i.e.,

$$
A(2 a)=2 A(a)
$$

for all $a \in X$. The mapping $A$ is a unique fixed point of $J$ in the set

$$
M=\{g \in S: d(h, g)<\infty\} .
$$

This implies that $A$ is a unique mapping satisfying (2.8) such that there exists a $\mu \in(0, \infty)$ satisfying

$$
\|g(a)-A(a)\| \leq \mu\left(2 \varphi(a, a)+\frac{1}{2} \varphi(2 a, a)\right)
$$

for all $a \in X$;

(2) $d\left(J^{l} g, A\right) \rightarrow 0$ as $l \rightarrow \infty$. This implies the equality

$$
\lim _{l \rightarrow \infty} \frac{1}{2^{l}} g\left(2^{l} a\right)=A(a)
$$

for all $a \in X$;

(3) $d(g, A) \leq \frac{1}{1-\alpha} d(g, g g)$, which implies the inequality

$$
d(g, A) \leq \frac{1}{1-\alpha} .
$$

So

$$
\|g(a)-A(a)\| \leq \frac{1}{1-\alpha}\left(2 \varphi(a, a)+\frac{1}{2} \varphi(2 a, a)\right)
$$

for all $a \in X$. 
It follows from (2.1) and (2.2) that

$$
\begin{aligned}
\|D A(a, b)\| & =\lim _{l \rightarrow \infty} \frac{1}{2^{l}}\left\|D g\left(2^{l} a, 2^{l} b\right)\right\| \\
& \leq \lim _{l \rightarrow \infty} \frac{1}{2^{l}}\left(\varphi\left(2^{l+1} a, 2^{l+1} b\right)+8 \varphi\left(2^{l} a, 2^{l} b\right)\right) \\
& \leq \lim _{l \rightarrow \infty} \frac{2^{l} \alpha^{l}}{2^{l}}(\varphi(2 a, 2 b)+8 \varphi(a, b))=0
\end{aligned}
$$

for all $a, b \in X$. Hence $D A(a, b)=0$ for all $a, b$. So $A: X \rightarrow Y$ is additive.

By Lemma 2.1 and (2.9),

$$
\begin{aligned}
\left\|f_{n}\left(2\left[x_{i j}\right]\right)-8 f_{n}\left(\left[x_{i j}\right]\right)-A_{n}\left(\left[x_{i j}\right]\right)\right\|_{n} & \leq \sum_{i, j=1}^{n}\left\|f\left(2 x_{i j}\right)-8 f\left(x_{i j}\right)-A\left(x_{i j}\right)\right\| \\
& \leq \sum_{i, j=1}^{n} \frac{1}{1-\alpha}\left(2 \varphi\left(x_{i j}, x_{i j}\right)+\frac{1}{2} \varphi\left(2 x_{i j}, x_{i j}\right)\right)
\end{aligned}
$$

for all $x=\left[x_{i j}\right] \in M_{n}(X)$. Thus $A: X \rightarrow Y$ is a unique additive mapping satisfying (2.3), as desired.

Corollary 2.3 Let $r, \theta$ be positive real numbers with $r<1$. Let $f: X \rightarrow Y$ be an odd mapping such that

$$
\left\|D f_{n}\left(\left[x_{i j}\right],\left[y_{i j}\right]\right)\right\|_{n} \leq \sum_{i, j=1}^{n} \theta\left(\left\|x_{i j}\right\|^{r}+\left\|y_{i j}\right\|^{r}\right)
$$

for all $x=\left[x_{i j}\right], y=\left[y_{i j}\right] \in M_{n}(X)$. Then there exists a unique additive mapping $A: X \rightarrow Y$ such that

$$
\left\|f_{n}\left(2\left[x_{i j}\right]\right)-8 f_{n}\left(\left[x_{i j}\right]\right)-A_{n}\left(\left[x_{i j}\right]\right)\right\|_{n} \leq \sum_{i, j=1}^{n} \frac{9+2^{r}}{2-2^{r}} \theta\left\|x_{i j}\right\|^{r}
$$

for all $x=\left[x_{i j}\right] \in M_{n}(X)$.

Proof The proof follows from Theorem 2.2 by taking $\varphi(a, b)=\theta\left(\|a\|^{r}+\|b\|^{r}\right)$ for all $a, b \in X$. Then we can choose $\alpha=2^{r-1}$ and we get the desired result.

Theorem 2.4 Let $\varphi: X^{2} \rightarrow[0, \infty)$ be a function such that there exists an $\alpha<1$ with

$$
\varphi(a, b) \leq \frac{\alpha}{2} \varphi(2 a, 2 b)
$$

for all $a, b \in X$. Let $f: X \rightarrow Y$ be an odd mapping satisfying (2.2). Then there exists a unique additive mapping $A: X \rightarrow Y$ such that

$$
\left\|f_{n}\left(2\left[x_{i j}\right]\right)-8 f_{n}\left(\left[x_{i j}\right]\right)-A_{n}\left(\left[x_{i j}\right]\right)\right\|_{n} \leq \sum_{i, j=1}^{n} \frac{\alpha}{1-\alpha}\left(2 \varphi\left(x_{i j}, x_{i j}\right)+\frac{1}{2} \varphi\left(2 x_{i j}, x_{i j}\right)\right)
$$

for all $x=\left[x_{i j}\right] \in M_{n}(X)$. 
Proof Let $(S, d)$ be the generalized metric space defined in the proof of Theorem 2.2.

Now we consider the linear mapping $J: S \rightarrow S$ such that

$$
J g(a):=2 g\left(\frac{a}{2}\right)
$$

for all $a \in X$.

It follows from (2.7) that

$$
\left\|g\left(x_{s t}\right)-2 g\left(\frac{x_{s t}}{2}\right)\right\| \leq 4 \varphi\left(\frac{x_{s t}}{2}, \frac{x_{s t}}{2}\right)+\varphi\left(x_{s t}, \frac{x_{s t}}{2}\right) \leq \alpha\left(2 \varphi\left(x_{s t}, x_{s t}\right)+\frac{1}{2} \varphi\left(2 x_{s t}, x_{s t}\right)\right)
$$

for all $x_{s t} \in X$. Thus $d(g, J g) \leq \alpha$. So

$$
d(g, A) \leq \frac{\alpha}{1-\alpha}
$$

The rest of the proof is similar to the proof of Theorem 2.2.

Corollary 2.5 Let $r, \theta$ be positive real numbers with $r>1$. Let $f: X \rightarrow Y$ be an odd mapping satisfying (2.10). Then there exists a unique additive mapping $A: X \rightarrow Y$ such that

$$
\left\|f_{n}\left(2\left[x_{i j}\right]\right)-8 f_{n}\left(\left[x_{i j}\right]\right)-A_{n}\left(\left[x_{i j}\right]\right)\right\|_{n} \leq \sum_{i, j=1}^{n} \frac{2^{r}+9}{2^{r}-2} \theta\left\|x_{i j}\right\|^{r}
$$

for all $x=\left[x_{i j}\right] \in M_{n}(X)$.

Proof The proof follows from Theorem 2.4 by taking $\varphi(a, b)=\theta\left(\|a\|^{r}+\|b\|^{r}\right)$ for all $a, b \in X$. Then we can choose $\alpha=2^{1-r}$ and we get the desired result.

Theorem 2.6 Let $\varphi: X^{2} \rightarrow[0, \infty)$ be a function such that there exists an $\alpha<1$ with

$$
\varphi(a, b) \leq 8 \alpha \varphi\left(\frac{a}{2}, \frac{b}{2}\right)
$$

for all $a, b \in X$. Let $f: X \rightarrow Y$ be an odd mapping satisfying (2.2). Then there exists a unique cubic mapping $C: X \rightarrow Y$ such that

$$
\left\|f_{n}\left(2\left[x_{i j}\right]\right)-2 f_{n}\left(\left[x_{i j}\right]\right)-C_{n}\left(\left[x_{i j}\right]\right)\right\|_{n} \leq \sum_{i, j=1}^{n} \frac{1}{4-4 \alpha}\left(2 \varphi\left(x_{i j}, x_{i j}\right)+\frac{1}{2} \varphi\left(2 x_{i j}, x_{i j}\right)\right)
$$

for all $x=\left[x_{i j}\right] \in M_{n}(X)$.

Proof Let $(S, d)$ be the generalized metric space defined in the proof of Theorem 2.2.

Replacing $y_{s t}$ by $x_{s t}$ and letting $g\left(x_{s t}\right):=f\left(2 x_{s t}\right)-2 f\left(x_{s t}\right)$ in (2.6), we get

$$
\left\|g\left(2 x_{s t}\right)-8 g\left(x_{s t}\right)\right\| \leq 4 \varphi\left(x_{s t}, x_{s t}\right)+\varphi\left(2 x_{s t}, x_{s t}\right)
$$

for all $x_{s t} \in X$. So

$$
\left\|g\left(x_{s t}\right)-\frac{1}{8} g\left(2 x_{s t}\right)\right\| \leq \frac{1}{4}\left(2 \varphi\left(x_{s t}, x_{s t}\right)+\frac{1}{2} \varphi\left(2 x_{s t}, x_{s t}\right)\right)
$$


for all $x_{s t} \in X$. Thus $d(g, J g) \leq \frac{1}{4}$. So

$$
d(g, A) \leq \frac{1}{4-4 \alpha} .
$$

The rest of the proof is similar to the proof of Theorem 2.2.

Corollary 2.7 Letr, $\theta$ be positive real numbers with $r<3$. Let $f: X \rightarrow Y$ be an odd mapping satisfying (2.10). Then there exists a unique cubic mapping $C: X \rightarrow Y$ such that

$$
\left\|f_{n}\left(2\left[x_{i j}\right]\right)-2 f_{n}\left(\left[x_{i j}\right]\right)-C_{n}\left(\left[x_{i j}\right]\right)\right\|_{n} \leq \sum_{i, j=1}^{n} \frac{9+2^{r}}{8-2^{r}} \theta\left\|x_{i j}\right\|^{r}
$$

for all $x=\left[x_{i j}\right] \in M_{n}(X)$.

Proof The proof follows from Theorem 2.6 by taking $\varphi(a, b)=\theta\left(\|a\|^{r}+\|b\|^{r}\right)$ for all $a, b \in X$. Then we can choose $\alpha=2^{r-3}$ and we get the desired result.

Theorem 2.8 Let $\varphi: X^{2} \rightarrow[0, \infty)$ be a function such that there exists an $\alpha<1$ with

$$
\varphi(a, b) \leq \frac{\alpha}{8} \varphi(2 a, 2 b)
$$

for all $a, b \in X$. Let $f: X \rightarrow Y$ be an odd mapping satisfying (2.2). Then there exists a unique cubic mapping $C: X \rightarrow Y$ such that

$$
\left\|f_{n}\left(2\left[x_{i j}\right]\right)-2 f_{n}\left(\left[x_{i j}\right]\right)-C_{n}\left(\left[x_{i j}\right]\right)\right\|_{n} \leq \sum_{i, j=1}^{n} \frac{\alpha}{4-4 \alpha}\left(2 \varphi\left(x_{i j}, x_{i j}\right)+\frac{1}{2} \varphi\left(2 x_{i j}, x_{i j}\right)\right)
$$

for all $x=\left[x_{i j}\right] \in M_{n}(X)$.

Proof Let $(S, d)$ be the generalized metric space defined in the proof of Theorem 2.2.

It follows from (2.11) that

$$
\begin{aligned}
\left\|g\left(x_{s t}\right)-8 g\left(\frac{x_{s t}}{2}\right)\right\| & \leq 4 \varphi\left(\frac{x_{s t}}{2}, \frac{x_{s t}}{2}\right)+\varphi\left(x_{s t}, \frac{x_{s t}}{2}\right) \\
& \leq \frac{\alpha}{4}\left(2 \varphi\left(x_{s t}, x_{s t}\right)+\frac{1}{2} \varphi\left(2 x_{s t}, x_{s t}\right)\right)
\end{aligned}
$$

for all $x_{s t} \in X$. Thus $d(g, J g) \leq \frac{\alpha}{4}$. So

$$
d(g, A) \leq \frac{\alpha}{4-4 \alpha} .
$$

The rest of the proof is similar to the proof of Theorem 2.2.

Corollary 2.9 Let $r, \theta$ be positive real numbers with $r>3$. Let $f: X \rightarrow Y$ be an odd mapping satisfying (2.10). Then there exists a unique cubic mapping $C: X \rightarrow Y$ such that

$$
\left\|f_{n}\left(2\left[x_{i j}\right]\right)-2 f_{n}\left(\left[x_{i j}\right]\right)-C_{n}\left(\left[x_{i j}\right]\right)\right\|_{n} \leq \sum_{i, j=1}^{n} \frac{2^{r}+9}{2^{r}-8} \theta\left\|x_{i j}\right\|^{r}
$$

for all $x=\left[x_{i j}\right] \in M_{n}(X)$. 
Proof The proof follows from Theorem 2.8 by taking $\varphi(a, b)=\theta\left(\|a\|^{r}+\|b\|^{r}\right)$ for all $a, b \in X$. Then we can choose $\alpha=2^{3-r}$ and we get the desired result.

\section{Hyers-Ulam stability of AQCQ-functional equation (1.3) in matrix normed spaces: even mapping case}

In this section, we prove the Hyers-Ulam stability of AQCQ-functional equation (1.3) in matrix normed spaces for an even mapping case.

Theorem 3.1 Let $\varphi: X^{2} \rightarrow[0, \infty)$ be a function such that there exists an $\alpha<1$ with

$$
\varphi(a, b) \leq 4 \alpha \varphi\left(\frac{a}{2}, \frac{b}{2}\right)
$$

for all $a, b \in X$. Let $f: X \rightarrow Y$ be an even mapping satisfying $f(0)=0$ and (2.2). Then there exists a unique quadratic mapping $Q: X \rightarrow Y$ such that

$$
\left\|f_{n}\left(2\left[x_{i j}\right]\right)-16 f_{n}\left(\left[x_{i j}\right]\right)-Q_{n}\left(\left[x_{i j}\right]\right)\right\|_{n} \leq \sum_{i, j=1}^{n} \frac{1}{2-2 \alpha}\left(2 \varphi\left(x_{i j}, x_{i j}\right)+\frac{1}{2} \varphi\left(2 x_{i j}, x_{i j}\right)\right)
$$

for all $x=\left[x_{i j}\right] \in M_{n}(X)$.

Proof Let $(S, d)$ be the generalized metric space defined in the proof of Theorem 2.2.

Let $x_{i j}=0$ and $y_{i j}=0$ except for $(i, j)=(s, t)$ in $(2.2)$.

Putting $y_{s t}=x_{s t}$ in (2.2), we get

$$
\left\|f\left(3 y_{s t}\right)-6 f\left(2 y_{s t}\right)+15 f\left(y_{s t}\right)\right\| \leq \varphi\left(y_{s t}, y_{s t}\right)
$$

for all $y_{s t} \in X$.

Replacing $x_{s t}$ by $2 y_{s t}$ in (2.2), we get

$$
\left\|f\left(4 y_{s t}\right)-4 f\left(3 y_{s t}\right)+4 f\left(2 y_{s t}\right)+4 f\left(y_{s t}\right)\right\| \leq \varphi\left(2 y_{s t}, y_{s t}\right)
$$

for all $y_{s t} \in X$.

By (3.1) and (3.2),

$$
\begin{aligned}
& \left\|f\left(4 y_{s t}\right)-20 f\left(2 y_{s t}\right)+64 f\left(y_{s t}\right)\right\| \\
& \quad \leq\left\|4\left(f\left(3 y_{s t}\right)-6 f\left(2 y_{s t}\right)+15 f\left(y_{s t}\right)\right)\right\|+\left\|f\left(4 y_{s t}\right)-4 f\left(3 y_{s t}\right)+4 f\left(2 y_{s t}\right)+4 f\left(y_{s t}\right)\right\| \\
& \quad=4\left\|f\left(3 y_{s t}\right)-6 f\left(2 y_{s t}\right)+15 f\left(y_{s t}\right)\right\|+\left\|f\left(4 y_{s t}\right)-4 f\left(3 y_{s t}\right)+4 f\left(2 y_{s t}\right)+4 f\left(y_{s t}\right)\right\| \\
& \quad \leq 4 \varphi\left(y_{s t}, y_{s t}\right)+\varphi\left(2 y_{s t}, y_{s t}\right)
\end{aligned}
$$

for all $y_{s t} \in X$. Replacing $y_{s t}$ by $x_{s t}$ and letting $g\left(x_{s t}\right):=f\left(2 x_{s t}\right)-16 f\left(x_{s t}\right)$ in (3.3), we get

$$
\left\|g\left(2 x_{s t}\right)-4 g\left(x_{s t}\right)\right\| \leq 4 \varphi\left(x_{s t}, x_{s t}\right)+\varphi\left(2 x_{s t}, x_{s t}\right)
$$

for all $x_{s t} \in X$. So

$$
\left\|g\left(x_{s t}\right)-\frac{1}{4} g\left(2 x_{s t}\right)\right\| \leq \frac{1}{2}\left(2 \varphi\left(x_{s t}, x_{s t}\right)+\frac{1}{2} \varphi\left(2 x_{s t}, x_{s t}\right)\right)
$$


for all $x_{s t} \in X$. Thus $d(g, J g) \leq \frac{1}{2}$. So

$$
d(g, A) \leq \frac{1}{2-2 \alpha}
$$

The rest of the proof is similar to the proof of Theorem 2.2.

Corollary 3.2 Let $r, \theta$ be positive real numbers with $r<2$. Let $f: X \rightarrow Y$ be an even mapping satisfying (2.10). Then there exists a unique quadratic mapping $Q: X \rightarrow Y$ such that

$$
\left\|f_{n}\left(2\left[x_{i j}\right]\right)-16 f_{n}\left(\left[x_{i j}\right]\right)-Q_{n}\left(\left[x_{i j}\right]\right)\right\|_{n} \leq \sum_{i, j=1}^{n} \frac{9+2^{r}}{4-2^{r}} \theta\left\|x_{i j}\right\|^{r}
$$

for all $x=\left[x_{i j}\right] \in M_{n}(X)$.

Proof The proof follows from Theorem 3.1 by taking $\varphi(a, b)=\theta\left(\|a\|^{r}+\|b\|^{r}\right)$ for all $a, b \in X$. Then we can choose $\alpha=2^{r-2}$ and we get the desired result.

Theorem 3.3 Let $\varphi: X^{2} \rightarrow[0, \infty)$ be a function such that there exists an $\alpha<1$ with

$$
\varphi(a, b) \leq \frac{\alpha}{4} \varphi(2 a, 2 b)
$$

for all $a, b \in X$. Let $f: X \rightarrow Y$ be an even mapping satisfying $f(0)=0$ and (2.2). Then there exists a unique quadratic mapping $Q: X \rightarrow Y$ such that

$$
\left\|f_{n}\left(2\left[x_{i j}\right]\right)-16 f_{n}\left(\left[x_{i j}\right]\right)-Q_{n}\left(\left[x_{i j}\right]\right)\right\|_{n} \leq \sum_{i, j=1}^{n} \frac{\alpha}{2-2 \alpha}\left(2 \varphi\left(x_{i j}, x_{i j}\right)+\frac{1}{2} \varphi\left(2 x_{i j}, x_{i j}\right)\right)
$$

for all $x=\left[x_{i j}\right] \in M_{n}(X)$.

Proof Let $(S, d)$ be the generalized metric space defined in the proof of Theorem 2.2.

It follows from (3.4) that

$$
\left\|g\left(x_{s t}\right)-4 g\left(\frac{x_{s t}}{2}\right)\right\| \leq 4 \varphi\left(\frac{x_{s t}}{2}, \frac{x_{s t}}{2}\right)+\varphi\left(x_{s t}, \frac{x_{s t}}{2}\right) \leq \frac{\alpha}{2}\left(2 \varphi\left(x_{s t}, x_{s t}\right)+\frac{1}{2} \varphi\left(2 x_{s t}, x_{s t}\right)\right)
$$

for all $x_{s t} \in X$. Thus $d(g, J g) \leq \frac{\alpha}{2}$. So

$$
d(g, A) \leq \frac{\alpha}{2-2 \alpha}
$$

The rest of the proof is similar to the proof of Theorem 2.2.

Corollary 3.4 Let $r, \theta$ be positive real numbers with $r>2$. Let $f: X \rightarrow Y$ be an even mapping satisfying (2.10). Then there exists a unique quadratic mapping $Q: X \rightarrow Y$ such that

$$
\left\|f_{n}\left(2\left[x_{i j}\right]\right)-16 f_{n}\left(\left[x_{i j}\right]\right)-Q_{n}\left(\left[x_{i j}\right]\right)\right\|_{n} \leq \sum_{i, j=1}^{n} \frac{2^{r}+9}{2^{r}-4} \theta\left\|x_{i j}\right\|^{r}
$$

for all $x=\left[x_{i j}\right] \in M_{n}(X)$. 
Proof The proof follows from Theorem 3.3 by taking $\varphi(a, b)=\theta\left(\|a\|^{r}+\|b\|^{r}\right)$ for all $a, b \in X$. Then we can choose $\alpha=2^{2-r}$ and we get the desired result.

Theorem 3.5 Let $\varphi: X^{2} \rightarrow[0, \infty)$ be a function such that there exists an $\alpha<1$ with

$$
\varphi(a, b) \leq 16 \alpha \varphi\left(\frac{a}{2}, \frac{b}{2}\right)
$$

for all $a, b \in X$. Let $f: X \rightarrow Y$ be an even mapping satisfying $f(0)=0$ and (2.2). Then there exists a unique quartic mapping $R: X \rightarrow Y$ such that

$$
\left\|f_{n}\left(2\left[x_{i j}\right]\right)-4 f_{n}\left(\left[x_{i j}\right]\right)-R_{n}\left(\left[x_{i j}\right]\right)\right\|_{n} \leq \sum_{i, j=1}^{n} \frac{1}{8-8 \alpha}\left(2 \varphi\left(x_{i j}, x_{i j}\right)+\frac{1}{2} \varphi\left(2 x_{i j}, x_{i j}\right)\right)
$$

for all $x=\left[x_{i j}\right] \in M_{n}(X)$.

Proof Let $(S, d)$ be the generalized metric space defined in the proof of Theorem 2.2.

Replacing $y_{s t}$ by $x_{s t}$ and letting $g\left(x_{s t}\right):=f\left(2 x_{s t}\right)-4 f\left(x_{s t}\right)$ in (3.3), we get

$$
\left\|g\left(2 x_{s t}\right)-16 g\left(x_{s t}\right)\right\| \leq 4 \varphi\left(x_{s t}, x_{s t}\right)+\varphi\left(2 x_{s t}, x_{s t}\right)
$$

for all $x_{s t} \in X$. So

$$
\left\|g\left(x_{s t}\right)-\frac{1}{16} g\left(2 x_{s t}\right)\right\| \leq \frac{1}{8}\left(2 \varphi\left(x_{s t}, x_{s t}\right)+\frac{1}{2} \varphi\left(2 x_{s t}, x_{s t}\right)\right)
$$

for all $x_{s t} \in X$. Thus $d(g, J g) \leq \frac{1}{8}$. So

$$
d(g, A) \leq \frac{1}{8-8 \alpha}
$$

The rest of the proof is similar to the proof of Theorem 2.2.

Corollary 3.6 Let $r, \theta$ be positive real numbers with $r<4$. Let $f: X \rightarrow Y$ be an even mapping satisfying (2.10). Then there exists a unique quartic mapping $R: X \rightarrow Y$ such that

$$
\left\|f_{n}\left(2\left[x_{i j}\right]\right)-4 f_{n}\left(\left[x_{i j}\right]\right)-R_{n}\left(\left[x_{i j}\right]\right)\right\|_{n} \leq \sum_{i, j=1}^{n} \frac{9+2^{r}}{16-2^{r}} \theta\left\|x_{i j}\right\|^{r}
$$

for all $x=\left[x_{i j}\right] \in M_{n}(X)$.

Proof The proof follows from Theorem 3.5 by taking $\varphi(a, b)=\theta\left(\|a\|^{r}+\|b\|^{r}\right)$ for all $a, b \in X$. Then we can choose $\alpha=2^{r-4}$ and we get the desired result.

Theorem 3.7 Let $\varphi: X^{2} \rightarrow[0, \infty)$ be a function such that there exists an $\alpha<1$ with

$$
\varphi(a, b) \leq \frac{\alpha}{16} \varphi(2 a, 2 b)
$$


for all $a, b \in X$. Let $f: X \rightarrow Y$ be an even mapping satisfying $f(0)=0$ and (2.2). Then there exists a unique quartic mapping $R: X \rightarrow Y$ such that

$$
\left\|f_{n}\left(2\left[x_{i j}\right]\right)-4 f_{n}\left(\left[x_{i j}\right]\right)-R_{n}\left(\left[x_{i j}\right]\right)\right\|_{n} \leq \sum_{i, j=1}^{n} \frac{\alpha}{8-8 \alpha}\left(2 \varphi\left(x_{i j}, x_{i j}\right)+\frac{1}{2} \varphi\left(2 x_{i j}, x_{i j}\right)\right)
$$

for all $x=\left[x_{i j}\right] \in M_{n}(X)$.

Proof Let $(S, d)$ be the generalized metric space defined in the proof of Theorem 2.2.

It follows from (3.5) that

$$
\begin{aligned}
\left\|g\left(x_{s t}\right)-16 g\left(\frac{x_{s t}}{2}\right)\right\| & \leq 4 \varphi\left(\frac{x_{s t}}{2}, \frac{x_{s t}}{2}\right)+\varphi\left(x_{s t}, \frac{x_{s t}}{2}\right) \\
& \leq \frac{\alpha}{8}\left(2 \varphi\left(x_{s t}, x_{s t}\right)+\frac{1}{2} \varphi\left(2 x_{s t}, x_{s t}\right)\right)
\end{aligned}
$$

for all $x_{s t} \in X$. Thus $d(g, J g) \leq \frac{\alpha}{8}$. So

$$
d(g, A) \leq \frac{\alpha}{8-8 \alpha} .
$$

The rest of the proof is similar to the proof of Theorem 2.2.

Corollary 3.8 Let $r, \theta$ be positive real numbers with $r>4$. Let $f: X \rightarrow Y$ be an even mapping satisfying (2.10). Then there exists a unique quartic mapping $R: X \rightarrow Y$ such that

$$
\left\|f_{n}\left(2\left[x_{i j}\right]\right)-4 f_{n}\left(\left[x_{i j}\right]\right)-R_{n}\left(\left[x_{i j}\right]\right)\right\|_{n} \leq \sum_{i, j=1}^{n} \frac{2^{r}+9}{2^{r}-16} \theta\left\|x_{i j}\right\|^{r}
$$

for all $x=\left[x_{i j}\right] \in M_{n}(X)$.

Proof The proof follows from Theorem 3.7 by taking $\varphi(a, b)=\theta\left(\|a\|^{r}+\|b\|^{r}\right)$ for all $a, b \in X$. Then we can choose $\alpha=2^{4-r}$ and we get the desired result.

\section{Competing interests}

The authors declare that they have no competing interests.

\section{Authors' contributions}

All authors conceived of the study, participated in its design and coordination, drafted the manuscript, participated in the sequence alignment, and read and approved the final manuscript.

\section{Author details}

${ }^{1}$ Department of Mathematics, Research Institute for Natural Sciences, Hanyang University, Seoul, 133-791, Korea.

${ }^{2}$ Department of Mathematics, Daejin University, Pocheon, Kyeonggi 487-711, Korea. ${ }^{3}$ Department of Mathematics, University of Seoul, Seoul, 130-743, Korea.

\section{Acknowledgements}

CP was supported by the Basic Science Research Program through the National Research Foundation of Korea funded by the Ministry of Education, Science and Technology (NRF-2012R1A1A2004299), and DYS was supported by the Basic Science Research Program through the National Research Foundation of Korea funded by the Ministry of Education, Science and Technology (NRF-2010-0021792). 


\section{References}

1. Ruan, ZJ: Subspaces of C $C^{*}$-algebras. J. Funct. Anal. 76, 217-230 (1988)

2. Effros, E, Ruan, ZJ: On approximation properties for operator spaces. Int. J. Math. 1, 163-187 (1990)

3. Choi, MD, Effros, E: Injectivity and operator spaces. J. Funct. Anal. 24, 156-209 (1977)

4. Effros, E, Ruan, ZJ: On the abstract characterization of operator spaces. Proc. Am. Math. Soc. 119, $579-584$ (1993)

5. Pisier, G: Grothendieck's theorem for non-commutative $C^{*}$-algebras with an appendix on Grothendieck's constants. J. Funct. Anal. 29, 397-415 (1978)

6. Haagerup, U: Decomp. of completely bounded maps (unpublished manuscript)

7. Effros, E: On Multilinear Completely Bounded Module Maps. Contemp. Math., vol. 62, pp. 479-501. Am. Math. Soc., Providence (1987)

8. Ulam, SM: A Collection of the Mathematical Problems. Interscience, New York (1960)

9. Hyers, DH: On the stability of the linear functional equation. Proc. Natl. Acad. Sci. USA 27, $222-224$ (1941)

10. Aoki, T: On the stability of the linear transformation in Banach spaces. J. Math. Soc. Jpn. 2, 64-66 (1950)

11. Rassias, TM: On the stability of the linear mapping in Banach spaces. Proc. Am. Math. Soc. 72, 297-300 (1978)

12. Găvruta, P: A generalization of the Hyers-Ulam-Rassias stability of approximately additive mappings. J. Math. Anal. Appl. 184, 431-436 (1994)

13. Rassias, TM: Problem 16; 2. Report of the 27th international symp. on functional equations. Aequ. Math. 39, 292-293, $309(1990)$

14. Gajda, Z: On stability of additive mappings. Int. J. Math. Math. Sci. 14, 431-434 (1991)

15. Rassias, TM, Šemrl, P: On the behaviour of mappings which do not satisfy Hyers-Ulam stability. Proc. Am. Math. Soc. 114, 989-993 (1992)

16. Czerwik, S: Functional Equations and Inequalities in Several Variables. World Scientific, Singapore (2002)

17. Hyers, DH, Isac, G, Rassias, TM: Stability of Functional Equations in Several Variables. Birkhäuser, Basel (1998)

18. Rassias, JM: On approximation of approximately linear mappings by linear mappings. J. Funct. Anal. 46, 126-130 (1982)

19. Skof, F: Proprietà locali e approssimazione di operatori. Rend. Semin. Mat. Fis. Milano 53, 113-129 (1983)

20. Cholewa, PW: Remarks on the stability of functional equations. Aequ. Math. 27, 76-86 (1984)

21. Czerwik, S: On the stability of the quadratic mapping in normed spaces. Abh. Math. Semin. Univ. Hamb. 62, 59-64 (1992)

22. Jun, K, Kim, H: The generalized Hyers-Ulam-Rassias stability of a cubic functional equation. J. Math. Anal. Appl. 274, 867-878 (2002)

23. Lee, S, Im, S, Hwang, I: Quartic functional equations. J. Math. Anal. Appl. 307, 387-394 (2005)

24. Aczel, J, Dhombres, J: Functional Equations in Several Variables. Cambridge University Press, Cambridge (1989)

25. Amyari, M, Park, C, Moslehian, MS: Nearly ternary derivations. Taiwan. J. Math. 11, 1417-1424 (2007)

26. Chou, CY, Tzeng, JH: On approximate isomorphisms between Banach *-algebras or $C^{*}$-algebras. Taiwan. J. Math. 10, 219-231 (2006)

27. Eshaghi Gordji, M, Savadkouhi, MB: Stability of a mixed type cubic-quartic functional equation in non-Archimedean spaces. Appl. Math. Lett. 23, 1198-1202 (2010)

28. Isac, G, Rassias, TM: On the Hyers-Ulam stability of $\psi$-additive mappings. J. Approx. Theory 72, 131-137 (1993)

29. Jun, K, Lee, Y: A generalization of the Hyers-Ulam-Rassias stability of the Pexiderized quadratic equations. J. Math. Anal. Appl. 297, 70-86 (2004)

30. Jung, S: Hyers-Ulam-Rassias Stability of Functional Equations in Mathematical Analysis. Hadronic Press, Palm Harbor (2001)

31. Park, C: Homomorphisms between Poisson JC ${ }^{*}$-algebras. Bull. Braz. Math. Soc. 36, 79-97 (2005)

32. Park, C, Ghaleh, SG, Ghasemi, K: n-Jordan *-homomorphisms in C*-algebras. Taiwan. J. Math. 16, 1803-1814 (2012)

33. Rassias, JM: Solution of a problem of Ulam. J. Approx. Theory 57, 268-273 (1989)

34. Cădariu, L, Radu, V: Fixed points and the stability of Jensen's functional equation. J. Inequal. Pure Appl. Math. 4(1) Article ID 4 (2003)

35. Diaz, J, Margolis, B: A fixed point theorem of the alternative for contractions on a generalized complete metric space. Bull. Am. Math. Soc. 74, 305-309 (1968)

36. Isac, G, Rassias, TM: Stability of $\psi$-additive mappings: applications to nonlinear analysis. Int. J. Math. Math. Sci. 19 219-228 (1996)

37. Cădariu, L, Radu, V: On the stability of the Cauchy functional equation: a fixed point approach. Grazer Math. Ber. 346 43-52 (2004)

38. Cădariu, L, Radu, V: Fixed point methods for the generalized stability of functional equations in a single variable. Fixed Point Theory Appl. 2008, Article ID 749392 (2008)

39. Jung, Y, Chang, I: The stability of a cubic type functional equation with the fixed point alternative. J. Math. Anal. Appl. 306, 752-760 (2005)

40. Mirzavaziri, M, Moslehian, MS: A fixed point approach to stability of a quadratic equation. Bull. Braz. Math. Soc. 37 , 361-376 (2006)

41. Park, C: Fixed points and Hyers-Ulam-Rassias stability of Cauchy-Jensen functional equations in Banach algebras. Fixed Point Theory Appl. 2007, Article ID 50175 (2007)

42. Park, C: Generalized Hyers-Ulam stability of functional equations: a fixed point approach. Taiwan. J. Math. 14, 1591-1608 (2010)

43. Radu, V: The fixed point alternative and the stability of functional equations. Fixed Point Theory 4, 91-96 (2003)

44. Eshaghi Gordji, M, Kaboli-Gharetapeh, S, Park, C, Zolfaghari, S: Stability of an additive-cubic-quartic functional equation. Adv. Differ. Equ. 2009, Article ID 395693 (2009)

45. Eshaghi Gordji, M, Abbaszadeh, S, Park, C: On the stability of a generalized quadratic and quartic type functional equation in quasi-Banach spaces. J. Inequal. Appl. 2009, Article ID 153084 (2009)

46. Mihet, D, Radu, V: On the stability of the additive Cauchy functional equation in random normed spaces. J. Math. Anal. Appl. 343, 567-572 (2008)

47. Park, C: Generalized Hyers-Ulam-Rassias stability of quadratic functional equations: a fixed point approach. Fixed Point Theory Appl. 2008, Article ID 493751 (2008) 
doi:10.1186/1687-1847-2013-146

Cite this article as: Park et al.: An AQCQ-functional equation in matrix Banach spaces. Advances in Difference Equations 2013 2013:146.

Submit your manuscript to a SpringerOpen ${ }^{\circ}$ journal and benefit from:

- Convenient online submission

- Rigorous peer review

- Immediate publication on acceptance

Open access: articles freely available online

- High visibility within the field

- Retaining the copyright to your article

Submit your next manuscript at $\boldsymbol{s p r i n g e r o p e n . c o m ~}$ 